University of Nebraska - Lincoln

DigitalCommons@University of Nebraska - Lincoln

$11-2009$

\title{
Communicative Correlates of Satisfaction, Family Identity, and Group Salience in Multiracial/Ethnic Families
}

Jordan Soliz

University of Nebraska-Lincoln, jsoliz2@unl.edu

Allison R. Thorson

University of San Francisco, athorson@usfca.edu

Christine E. Rittenour

West Virginia University, Christine.Rittenour@mail.wvu.edu

Follow this and additional works at: https://digitalcommons.unl.edu/commstudiespapers

Part of the Gender, Race, Sexuality, and Ethnicity in Communication Commons, International and Intercultural Communication Commons, Interpersonal and Small Group Communication Commons, and the Social Psychology Commons

Soliz, Jordan; Thorson, Allison R.; and Rittenour, Christine E., "Communicative Correlates of Satisfaction, Family Identity, and Group Salience in Multiracial/Ethnic Families" (2009). Papers in Communication Studies. 7.

https://digitalcommons.unl.edu/commstudiespapers/7

This Article is brought to you for free and open access by the Communication Studies, Department of at DigitalCommons@University of Nebraska - Lincoln. It has been accepted for inclusion in Papers in Communication Studies by an authorized administrator of DigitalCommons@University of Nebraska - Lincoln. 


\title{
Communicative Correlates of Satisfaction, Family Identity, and Group Salience in Multiracial/Ethnic Families
}

\author{
Jordan Soliz \\ Department of Communication Studies, University of Nebraska-Lincoln, \\ 433 Oldfather Hall, Lincoln, NE 68588-0329; jsoliz2@unl.edu \\ Allison R. Thorson \\ University of San Francisco, 2130 Fulton Street, San Francisco, CA 94117. \\ Christine E. Rittenour \\ Department of Communication Studies, West Virginia University, \\ 108 Armstrong Hall, PO Box 6293, Morgantown, WV 26506.
}

\begin{abstract}
Guided by the Common Ingroup Identity Model (S. L. Gaertner \& J. F. Dovidio, 2000) and Communication Accommodation Theory (C. Shepard, H. Giles, \& B. A. LePoire, 2001), we examined the role of identity accommodation, supportive communication, and self-disclosure in predicting relational satisfaction, shared family identity, and group salience in multiracial/ ethnic families. Additionally, we analyzed the association between group salience and relational outcomes as well as the moderating roles of multiracial/ethnic identity and marital status. Individuals who have parents from different racial/ethnic groups were invited to complete questionnaires on their family experiences. Participants $(\mathrm{N}=139)$ answered questions about relationships with mothers, fathers, and grandparents. The results of the multilevel modeling analyses are discussed in terms of implications for understanding multiracial/ethnic families and family functioning.
\end{abstract}

Keywords: communication, family processes, interracial, ethnic, multilevel modeling, race, ethnicity
R esearch on interracial/ethnic contact has tradRitionally focused on group-based conflict or contact, or both, between strangers of different racial/ethnic groups (Brown \& Hewstone, 2005). Recent scholarship focuses on more personal contact such as that which takes place within friendships (e.g., Diggs \& Clark, 2002) and romantic relationships (e.g., Foeman \& Nance, 2002). Given the increasing prevalence of interracial/ethnic families, scholars should focus on understanding family functioning and communication in these relationships (Orbe, 1999) as interactions in multiracial/ ethnic families may be affected by the macrosocietal influences of the differing racial/ethnic identities. This can create unique circumstances for individuals and the family as a whole. Thus, guided by intergroup theorizing, the current study addresses this need by investigating family communication, identity concerns, and relational outcomes from the perspective of the multiracial/ethnic individuals. 
In 1967, the U.S. Supreme Court's decision in Loving $v$. Virginia put an end to state-constituted bans on interracial marriages. Since this court decision, there has been a steady increase in interracial/ethnic marriages. According to the latest U.S. Census, $7.4 \%$ of marriages are composed of individuals from different ethnic/racial backgrounds and, throughout the literature, estimates range that $5 \%$ to $10 \%$ of families are made up of individuals with different racial/ethnic backgrounds. The number of popular press books, websites, and the like serve as further evidence of the increase in this family form. Scholars are devoting more attention to learning about individuals' experiences as members of multiracial/ethnic families (e.g., Root, 2003) including the identity and experience of multiracial/ethnic children. Specifically, multiracial/ethnic individuals and their familial experiences "challenge received notions of family, community, and identity" (Wallace, 2004, p. 196). As the idea of multiracial/ethnic identity receives more scholarly attention (Phinney, 2000), researchers recognize the multidimensional aspect of identity for these individuals. For instance, more recent theorizing (e.g., Rockquemore \& Brunsma, 2002; Root, 2003) extends multiracial/ethnic identity "options" from traditional dichotomous (monoracial/ethnic vs. biracial/ multiethnic) views to more diverse identity "choices" (e.g., a protean identity in which individuals embrace a racial/ethnic identity depending on the context and goals of an interaction).

Whereas these experiences can lead to greater appreciation of multiculturalism resulting in less favoritism of one's racial/ethnic group and discrimination of others, individuals' experiences may also negatively affect their overall wellbeing (Vivero \& Jenkins, 1999). Specifically, when monoracial/ethnic identity is the norm, individuals may struggle with selecting a particular group with which to identify, establishing the authenticity of the identity, and experiencing marginalization through their group membership (Root, 1996). In fact, Vivero and Jenkins coined the term "cultural homelessness" to demonstrate the lack of a sense of belonging and identification with a racial/ethnic group. Obviously, several of these findings paint a somewhat bleak picture of the multiracial/ethnic experience and, thus, multiple books and guides have been written to assist parents and family practitioners. The current study attempts to broaden our understanding of these family experiences by addressing three key limitations of the extant research.

First, a majority of the research focuses on the experiences of African American/European American couples and their children. Although this is important considering the historically disapproving societal attitudes that these families face, the research is limited in its inclusion of other races/ethnicities. Although it is likely that there are similarities and differences in family interaction on the basis of racial/ethnic backgrounds and the corresponding cultural orientations (Sillars, 1995), our goal in this sense is not to presume or examine similarities and differences between participants from a select group of racial/ethnic backgrounds. Rather, our purpose is to attain a more diverse sample of multiracial/ethnic individuals to gain a general sense of family experiences while taking into account factors that may affect family relationships. Second, whereas much of the research takes a unidirectional perspective in examining what factors influence children's identity, well-being, and so forth, we investigate the manner in which identity influences the relationship between the child and other family members. Third, as an often overlooked component in multiracial/ ethnic research, communication is central to the understanding of family functioning and, hence, serves as a focal point in this analysis. In addressing these limitations, we take an intergroup perspective on families and, thus, we now outline the theoretical impetus for the study.

\section{Intergroup Communication and Multiracial/Ethnic Families}

An intergroup perspective maintains that achieving psychological distinctiveness and inclusiveness is an inherent part of human relations. As such, we make sense of the world in terms of the social groups (e.g., race/ethnicity, religion, age, nationality) to which we belong (i.e., ingroups) and those which constitute out-groups. According to intergroup theorizing, social categorization leads to intergroup comparison (e.g., stereotyping of out-group members, prejudice, intergroup anxiety, uncertainty about out-group members). Thus, interactions with in-group members are typically more positive and satisfying compared to those with members of an out-group (Harwood \& Giles, 2005) 
Traditionally, families have been viewed as an intragroup context in which perceptions of inclusiveness and solidarity create more personal relationships and positive experiences as we are interacting with members of a social in-group. Many family relationships, however, can be and often are influenced by the various and different social identities of family members (Harwood, Soliz, \& Lin, 2006). Thus many personal and family relationships can be characterized as intergroup in that the communication that constitutes these relationships may, at times, reflect divergent social identities. For instance, interfaith relationships (Hughes \& Dickson, 2005), heterosexual-homosexual friendships (Vonofakou, Hewstone, \& Voci, 2007), and intergenerational relationships (Soliz \& Harwood, 2006) all represent contexts in which understanding of the relationship and interaction(s) may be enhanced by taking into account the larger macrolevel social influences (Harwood \& Giles, 2006). For instance, the presence of age distinctions and the corresponding young adult (i.e., in-group) versus older adults (i.e., out-group) comparison is one of the factors that differentiates positive and negative grandparent-grandchild relationships in that age distinctions are associated with less satisfying relationships (Soliz \& Harwood).

One of the themes emerging from research on multiracial/ethnic families is the blurring of what constitutes racial/ethnic in-groups and out-groups. Likewise, an important aspect of multiracial/ethnic identity is managing in-group membership (Williams, 1996). In short, in multiethnic/ racial families, racial/ethnic differences may, at times, be salient and act as a barrier to positive family functioning. Of course, this is not to suggest that all family interactions are influenced by divergent social identities. Rather, intergroup theorizing also emphasizes the significance of a perceived common in-group identity. As Gaertner and Dovidio (2000) explain in their Common Ingroup Identity Model, perceived social differences can be ameliorated by (re)conceptualizing the relationship in terms of a shared identity. Although typically applied to nonpersonal contexts, their Common Ingroup Identity Model has guided a growing body of research on families (e.g., Soliz \& Harwood, 2006) by demonstrating that differences in a family can be transcended through perceptions of a common familial identity. Thus, a perceived sense of shared family identity in multiracial/ethnic families would sug- gest a minimal recognition and, more importantly, minimal influence of differences that are based on racial/ethnic identity. In fact, Byrd and Garwick (2006) attest to this, as they suggest that "coming together" and building a shared relational culture are important in developing harmonious interracial/ ethnic relationships.

One of the often-overlooked principal factors associated with perceptions of a common in-group identity and the quality of intergroup interactions, in general, is the nature of the communication. In multiracial/ethnic families, communication (e.g., language, content, style) may vary among family members depending on their perceived sense of racial/ethnic affiliation or distinctiveness. In fact, the uncertainty of what is expected in terms of interactions with family members may lead to feelings of anxiety and general discomfort (Vivero \& Jenkins, 1999). In this sense, as a guiding theory of intergroup contact, Communication Accommodation Theory (CAT; Shepard, Giles, \& LePoire, 2001) provides a theoretical framework for investigating communication in multiracial/ethnic families, as it emphasizes the relationship between communication and group-based categorization. Originally conceived to understand linguistic shifts in interethnic interactions, CAT has evolved into a theory that addresses various accommodative and nonaccomodative dimensions of communication (e.g., discourse management, accent and dialect shift, interpersonal control strategies) and their role in moderating sociopsychological distinctiveness in interactions. For example, we may appropriately accommodate communication behavior to the expectations or standards of others as a way of seeking approval, inclusion, affiliation, or interpersonal goals. Conversely, nonaccommodation may be a strategy for communicating social distinctiveness. Accommodative behaviors are typically associated with more positive perceptions of the interaction or relationship because the context is more personalized whereas nonaccommodation can accentuate the intergroup distinction (i.e., group differences) and, thus, is perceived more negatively.

Harwood, Soliz, et al. (2006) position CAT as a theoretical framework for understanding family interactions, especially those in which group-based distinctions may be evident. For example, researchers of grandparent-grandchild relationships have investigated the influence of (non)accommodative behaviors (e.g., providing wisdom, complaining, 
patronizing communication, storytelling, self-disclosure) on perceptions of age differences and relational outcomes (Harwood, Raman, \& Hewstone, 2006; Soliz \& Harwood, 2006). Thus, extending this research to the current context, we investigate the relationship between three accommodative behaviors-supportive communication, self-disclosure, and identity accommodation - and relational outcomes such as satisfaction, perceptions of shared family identity, and group salience in multiracial/ ethnic families. By invoking CAT, our goal is to understand the dynamics of family communication that might illuminate or minimize the potential effects of racial/ethnic difference on the relationship between family members.

Both supportive communication and self-disclosure have been established as important aspects of solidarity and satisfaction in interpersonal relationships (Burleson \& MacGeorge, 2004). From a CAT perspective, these variables represent accommodative behaviors in that, in being more person centered, supportive communication and selfdisclosure are associated with more personalized conceptualizations of the relationship and, hence, perceived positively. Likewise, they are negatively associated with intergroup distinctions (Brown \& Hewstone, 2005; Soliz \& Harwood, 2006).

In addition to these accommodative behaviors, attention should also be paid to those behaviors that focus specifically on the racial/ethnic identity of family members. Orbe (1999) outlines various ways families may approach communicating about race and ethnicity and discusses relevant positive and negative consequences. One of the family communication practices is "affirming the multiethnic experience." Although he points out that there is not an ideal way for families to discuss multiethnicity, there is strong support (e.g., Root's 1996 Bill of Rights for People of Mixed Heritage) that affirming the multiracial/ethnic heritage of individuals may lead to more positive outcomes. Moreover, parents' recognition and discussion of children's mixed heritage and being active in the socialization of identity is an objective of many parents in these relationships (Byrd \& Garwick, 2006; McFadden, 2001). These examples represent the notion of identity accommodation that involves communicatively recognizing and affirming the multiracial/ethnic heritage of family members. Like supportive communication and self-disclosure, we expect this accommodative behavior to be associated with relational satisfaction and a sense of shared family identity.
H1. Perceptions of supportive communication, self-disclosure, and identity accommodation are positively associated with relational satisfaction.

H2. Perceptions of supportive communication, self-disclosure, and identity accommodation are positively associated with shared family identity.

Harwood, Raman, et al. (2006) define group salience as "an individual's awareness of group memberships and respective group differences in an intergroup encounter" (p. 182). Much of the discussion thus far has centered on the recognition (or lack thereof) of racial/ethnic group differences (i.e., group salience) in the relationships. In fact, much of the discomfort or anxiety children discuss in interactions with family members may be attributed to different cultural orientations (Vivero \& Jenkins, 1999), which is indicative of racial/ethnic group salience. Whereas perceptions of racial/ethnic group differences can be attributed to contextual factors (e.g., community demographics, physical appearance), they are also linked to communication (Harwood, Raman, et al., 2006). Because accommodative behaviors are typically perceived as more personalized in nature, we expect supportive communication, self-disclosure, and identity accommodation to be negatively associated with group salience.

H3. Perceptions of supportive communication, self-disclosure, and identity accommodation are negatively associated with group salience.

As discussed, intergroup theory suggests that encounters conceptualized as intergroup (i.e., characterized by racial/ethnic group salience) are typically perceived as more negative than those deemed more personal. In this vein, group salience would be a hindrance to building common in-group identity in the family and harmonious relationships.

\section{H4. Group salience is negatively associated with relational satisfaction. \\ H5. Group salience is negatively associated with shared family identity.}

\section{Multiracial/Ethnic Identity and Marital Status}

The hypothesized relationships between communication and relational outcomes put forth thus far emerge from intergroup theorizing. The broader family literature, however, reveals two 
potential moderators of these relationships: racial/ ethnic identity of the adult child and marital status of his or her parents. Reflecting on the preceding discussion of identity, individuals may opt for mono-racial/ethnic identities (i.e., actively or passively disregarding the heritage of one family) or some manner of multiracial/ethnic identity (Rockquemore \& Brunsma, 2002; Root, 2003). Although considerable attention has been given to the communal and familial factors influencing identity as part of the socialization of the child, we know little about how multiracial/ethnic identity, in turn, affects family relationships when considering adult children. For example, does a monoracial/ethnic disposition create a sense of affiliation with some family members and distinctiveness with others? Does multiracial/ethnic identity mean one embraces or rejects the heritage of both sides of the family? Thus, given the significance of factors associated with identity and categorization (e.g., shared family identity), it is likely that the degree to which a family member identifies as "multiracial/ethnic" - as opposed to "mono-racial/ethnic" - would play an important role in family interactions and group-based categorization.

The potential effects of parental separation on children's well-being and relationships with parents and grandparents have been well documented (Amato \& Keith, 1991). Although some studies show similar levels of relational turbulence in inter- and intra-ethnic relationships (Troy, Lewis-Smith, \& Laurenceau, 2006), interracial/ ethnic couples have higher rates of divorce and, moreover, are less likely to marry or cohabitate after having a child out of wedlock (Brunsma, 2005). Thus, given the consequences of parental separation and its prevalence in multiracial/ethnic families and the importance of identity, we put forth the following research question: Do multiracial/ ethnic identity and marital status of the parents moderate the relationship between family communication and the outcomes of relational satisfaction, shared family identity, and group salience?

\section{Method}

\section{Participants}

The study employed a one-with-many design (Kenny, Kashy, \& Cook, 2006) in that participants answered questions about relationships with family members. Individuals who had parents from different racial/ethnic backgrounds were solicited from classes at a large Midwestern university and personal social networks. Likewise, we solicited participation from relevant online chatrooms and listservs. A total of 139 participants ranging in age from 19 to 53 years $(M=26.27, S D=8.13)$ completed an online questionnaire $(75.5 \%$ female: $24.5 \%$ male). Participants represented a variety of racial/ethnic backgrounds and provided various degrees of specifics in terms of their heritage. For instance, whereas some participants indicated more general panethnic identities (e.g., Asian and Hispanic), other participants provided more specific information (e.g., Japanese American and Mexican American, Native American and African American, Irish and Korean American) in describing their heritage. Given that our purpose was to include a more diverse sample of multiracial/ethnic individuals rather than focus on similarities or differences between a select grouping of multiracial/ethnic backgrounds as is the trend in the extant research, we were not concerned with creating a categorization process for our participants in terms of their multiracial/ethnic background.

Participants were given the opportunity to answer questions about their mother, father, a maternal grandparent, a paternal grandparent, or a combination of these. In total, participants answered questions about 444 family members $(M=3.19, S D$ $=0.88): 47.5 \%$ four family members, $26.6 \%$ three family members, $23.7 \%$ two family members, $2.2 \%$ one family member. In response to whether or not their parents were currently married, 94 reported "yes" and 45 reported "no."

\section{Measures}

Unless noted, all items were measured using 5-point Likert-type scales. Reliability is reported as ranges for some of the measures, as participants assessed multiple family relationships. Descriptive statistics and intercorrelations of the variables are presented in Table 1.

Relational satisfaction. Relational satisfaction was measured with an adapted version of the Marital Opinion Questionnaire (Huston, McHale, \& Crouter, 1986). Specific dimensions of satisfaction are assessed with eight semantic differentials on a 7-point scale (e.g., miserable/ enjoyable; hopeful/discouraging), with higher scores indicating higher satisfaction $(a=.92-.96)$. 
Table 1. Means, Standard Deviations, and Intercorrelations of Variables

\begin{tabular}{|c|c|c|c|c|c|c|c|}
\hline & 1 & 2 & 3 & 4 & 5 & 6 & 7 \\
\hline 1. Relational satisfaction & - & & & & & & \\
\hline 2. Shared family identity & .684 & - & & & & & \\
\hline 3. Supportive communication & .760 & .544 & - & & & & \\
\hline 4. Self-disclosure & .576 & .417 & .656 & - & & & \\
\hline 5. Identity accommodation & .489 & .358 & .487 & .452 & - & & \\
\hline 6. Group salience & -.236 & -.163 & -.290 & -.129 & -.228 & - & \\
\hline 7. Multiracial/ethnic identity & -.083 & -.020 & -.122 & -.022 & .003 & .035 & - \\
\hline Mean & 5.37 & 4.17 & 3.51 & 2.97 & 3.15 & 2.85 & 3.46 \\
\hline Standard deviation & 1.41 & .81 & 1.20 & 1.07 & .81 & 1.11 & 1.09 \\
\hline
\end{tabular}

Statistical significance of the intercorrelations is not reported because of the nonindependent nature of the data.

Shared family identity. Shared family identity was measured with a six-item scale (Soliz \& Harwood, 2006) that assesses the extent to which individuals identify as members of the same family (e.g., "I am proud to be in the same family as this [family member]"; "I feel as we are members of one family."). Higher scores indicate a greater shared family identity $(a=.79-.85)$.

Supportive communication. Supportive communication was measured with a slightly modified six-item version of the support subscale of the Quality of Relationships Inventory (Pierce, Sarason, \& Sarason, 1991; e.g., "I can you turn to [family member] for advice about problems."). Higher scores represent higher levels of support $(a=.92-.94)$.

Self-disclosure. Self-disclosure was assessed with six items derived from Laurenceau, Barrett, and Pietromonaco's (1998) work (e.g., "How much do you express your feelings? How much personal information does this [family member] disclose to you?"). On the basis of the notion that self-disclosure is a reciprocal communication phenomenon, the measure assesses a participants' perceptions of their own self-disclosure and perceptions of their family member's self-disclosure as an overall metric of reciprocal self-disclosure in the relationship. Higher scores represent higher levels of perceived self-disclosure in the relationship $(a=.88-.93)$.

Identity accommodation. On the basis of the tenets of accommodation theory and previous research, eight items were developed to assess a family member's tendency to communicatively recognize, appreciate, and affirm (a) his or her own racial/ethnic heritage (e.g., "My mother encourages me to learn about her racial/ethnic group."), (b) his or her (ex-)spouse's racial/ethnic heritage (e.g., "My father talks negatively about my mother's racial/ethnic group [R]."), and (c) the participant's multiracial/ethnic background (e.g., "My grandparent and I frequently discuss my experiences being biracial/multiethnic."). To determine if the items represented three distinct constructs of racial/ethnic identity accommodation, a confirmatory factor analysis (CFA) was conducted using LISREL 8.7. Because most participants answered questions about a mother and father, the CFA was conducted on responses for these family members. Results were poor for a three-factor solution, and modifications to achieve a proper-fitting model implied a one-dimensional construct: mothers, $\chi^{2}(15)=25.45, p=.044$, nonnormed fit index $(\mathrm{NNFI})=.95$, comparative fit index $(\mathrm{CFI})$ $=.98$, root mean square error of approximation $($ RMSEA $)=.073$; fathers, $\chi^{2}(15)=22.41, p=.097$, NNFI $=.96, \mathrm{CFI}=.98$, RMSEA $=.059$. Thus, the eight items were averaged for a general assessment of identity accommodation with higher scores representing higher levels of accommodation $(a=.72-.77)$.

Group salience. Adapted from previous research (Brown, Vivian, \& Hewstone, 1999), racial/ethnic group salience was measured with four items that assessed the degree to which participants per- 
ceived group differences in interactions with a family member (e.g., "How aware are you of any racial/ethnic difference between yourself and [family member]?" "How much does race/ethnicity matter when communicating with [family member]?"). Higher scores represent higher levels of group salience $(a=.74-.85)$.

Multiracial/ethnic identity. On the basis of the literature on multiethnic and biracial identity, four items were developed to assess the degree to which individuals embraced a multiracial/ethnic identity (e.g., "I typically identify or more often identify with one racial/ethnic group"; "I typically identify or more often identify with being biracial/multiethnic."). In other words, rather than identifying with only one parent's heritage, higher scores indicate a greater sense of identifying as multiracial/ethnic $(a=.81)$.

\section{Results}

In a one-with-many design, each participant is associated with multiple targets - in this case, family members. Thus, to test the hypotheses and address the research question while taking into account the interdependence of the data, multilevel modeling (MLM) using HLM 6.0 was used, with each participant serving as the "group" (i.e., second-level data) and thus representing the familylevel data. Hence, marital status and multiracial/ ethnic identity represented second-level variables because they are constant across each family group whereas the communicative and relational constructs served as first-level data because they were assessed for each relationship (e.g., mother, father) in the family "group." Additionally, age and sex of the subject were included as control variables. Interval variables were grand-mean centered (Hox, 2002). Dummy coded variables - sex (0 $=$ male, $1=$ female $)$ and marital status of parents $(0$ $=$ married, $1=$ not married - -were uncentered. All estimation was based on full maximum likelihood with robust standard errors.

The first analysis tests $\mathrm{H} 1$ and results are presented in Table 2. Procedures for the analysis followed Hox's (2002) steps for MLM. First, a baseline model was computed to determine significant between-group variance of relational satisfaction. In this step, no explanatory variables were in- cluded. The between-group variance was .55746 and the within-group variance was 1.43862 (Model 1). Approximately $28 \%$ of the variance in relational satisfaction was accounted for by differences associated with group-level (i.e., participants) factors. Therefore, this result suggests that the first-level data were not independent and hierarchical analysis was warranted. In the second step, the first-level explanatory variables were entered as fixed components (Model 2). In this Level 1 fixed effects model, all predictors were significant and accounted for approximately $53 \%$ of the within-group variance. In accordance with step three of Hox's proposed method of analysis, the second-level variables-multiracial/ ethnic identity, marital status, age, and sex-were included as predictors (Model 3). Marital status was a significant predictor, but multiracial/ethnic identity, age, and sex were not. Overall, the first and second level variables accounted for approximately $84 \%$ of the between-group variance.

In the fourth step, we first determined if any of the first-level predictors had a significant between-group variance component. Hox (2002) suggests that "testing for random slope variation is best done on a variable-by-variable basis" (p. 52). Supportive communication had a significant random effect $(p<.05)$, but identity accommodation $(p>.50)$ did not. Self-disclosure was marginally significant $(p=.086)$. Therefore, a random coefficients model was run with variance component estimates for supportive communication and selfdisclosure (Model 4). In the fifth step, cross-level interactions between the second-level variables and the two variables with significant random coefficients were assessed to address the research question. Results are presented in Model 5. Overall, this final model accounted for approximately $75 \%$ of the between-group variance and approximately $61 \%$ of the within-group variance on the basis of the baseline model. For each model, a deviance statistic with the corresponding parameters was calculated to represent the fit between the model and the data.

On the basis of the final results of this first MLM analysis (see Table 2, Model 5), H1 was supported in that supportive communication, selfdisclosure, and identity accommodation were all positively associated with relational satisfaction. Moreover, results suggest that the relationship between supportive communication (and, to 
Table 2. Analysis 1: Communicative Predictors of Relational Satisfaction

\begin{tabular}{|c|c|c|c|c|c|}
\hline & Model 1 & Model 2 & Model 3 & Model 4 & Model 5 \\
\hline \multicolumn{6}{|l|}{ Level 1} \\
\hline Intercept & $5.354^{* *}$ & $5.362^{* *}$ & $5.439^{* *}$ & $5.426^{* *}$ & $5.470^{* *}$ \\
\hline Supportive communication (SC) & & $.723^{* *}$ & $.709 * *$ & $.697^{* *}$ & $.593^{* *}$ \\
\hline Self-disclosure (SD) & & $.136^{*}$ & $.146^{* *}$ & $.166^{* *}$ & $.189 * *$ \\
\hline Identity accommodation (IA) & & $.210^{* *}$ & $.209^{* *}$ & $.159^{*}$ & $.150^{*}$ \\
\hline \multicolumn{6}{|l|}{ Level 2} \\
\hline Multiracial/ethnic identity (MI) & & & .011 & -.014 & .019 \\
\hline Marital status (MS) & & & $-.287^{*}$ & $-.180 \dagger$ & $-.260^{*}$ \\
\hline $\operatorname{Sex}(S)$ & & & .017 & .009 & -.042 \\
\hline Age (A) & & & -.006 & -.001 & -.009 \\
\hline \multicolumn{6}{|l|}{ Cross-level } \\
\hline $\mathrm{MI} \times \mathrm{SC}$ & & & & & -.021 \\
\hline $\mathrm{MI} \times \mathrm{SD}$ & & & & & -.041 \\
\hline $\mathrm{MS} \times \mathrm{SC}$ & & & & & $.275^{*}$ \\
\hline $\mathrm{MS} \times \mathrm{SD}$ & & & & & -.075 \\
\hline $\mathrm{S} \times \mathrm{SC}$ & & & & & -.007 \\
\hline $\mathrm{S} \times \mathrm{SD}$ & & & & & .073 \\
\hline $\mathrm{A} \times \mathrm{SC}$ & & & & & .001 \\
\hline $\mathrm{A} \times \mathrm{SD}$ & & & & & .012 \\
\hline \multicolumn{6}{|l|}{ Variance component } \\
\hline Intercept & & & & $.141^{* *}$ & $.137^{* *}$ \\
\hline $\mathrm{SC}$ & & & & $.002 *$ & $.032 * *$ \\
\hline SD & & & & $.048^{* *}$ & $.002^{* *}$ \\
\hline Deviance (parameters) & $1531.72(3)$ & $1147.11(6)$ & $1137.93(10)$ & $1113.67(15)$ & $1097.88(23)$ \\
\hline
\end{tabular}

$\dagger p<.07 ;{ }^{*} p<.05 ;{ }^{* *} p<.01$

a lesser extent, self-disclosure) and relational satisfaction varied across families, whereas the predictive power of identity accommodation was relatively stable. In terms of the research question, marital status emerged as the only moderator of the relationship between supportive communication and relational satisfaction. To decompose the interaction, we examined slopes $(b)$ for supportive communication in a regression equation at the two levels of the marital status variable (Aiken \& West, 1991). Supportive communication had a higher association with relational satisfaction for nonmarried families, $b=1.035$, compared to married families, $b=.783$. In both cases, supportive communication was positively associated with relational satisfaction.

The second analysis addresses $\mathrm{H} 2$ and follows the same steps as the previous analysis (Table 3). The baseline model (Model 1) showed that approximately $21 \%$ of the variance in shared family identity could be attributed to group-level factors (between-group variance $=.13743$; within-group variance $=.51862$ ). The fixed effects model (Model 2) accounted for approximately $29 \%$ of the withingroup variance with only supportive communication emerging as a significant predictor. As depicted in Model 3, marital status was a significant predictor of shared family identity. In total, this model accounted for approximately $47 \%$ of the between-group variance. Although identity accommodation did not have a significant random effect $(p=.393)$, self-disclosure and supportive communication $(p<.05)$ were statistically significant. Results for the random coefficients model are depicted in Model 4. Finally, relevant cross-level interactions were included (Model 5) and this final model accounted for approximately $39 \%$ of the between-group variance and approximately $48 \%$ of the within-group variance of the baseline model.

On the basis of this analysis, H2 was partially supported in that supportive communication and self-disclosure were positively associated with 
Table 3. Analysis 2: Communicative Predictors of Shared Family Identity

\begin{tabular}{|c|c|c|c|c|c|}
\hline & Model 1 & Model 2 & Model 3 & Model 4 & Model 5 \\
\hline \multicolumn{6}{|l|}{ Level 1} \\
\hline Intercept & $4.164^{* *}$ & $4.164^{* *}$ & $4.270^{* *}$ & $4.235^{* *}$ & $4.256^{* *}$ \\
\hline Supportive communication (SC & & $.300^{* *}$ & $.287^{* *}$ & $.250^{* *}$ & $.156^{* *}$ \\
\hline Self-disclosure (SD) & & .067 & .074 & $.087^{*}$ & $.124^{*}$ \\
\hline Identity accommodation (IA) & & $.079 \dagger$ & $.079 \dagger$ & .061 & .048 \\
\hline \multicolumn{6}{|l|}{ Level 2} \\
\hline Multiracial/ethnic identity (MI & & & .043 & .029 & .036 \\
\hline Marital status (MS) & & & $-.215^{*}$ & -.114 & $-.197^{*}$ \\
\hline $\operatorname{Sex}(S)$ & & & -.051 & -.019 & -.037 \\
\hline Age (A) & & & -.001 & -.004 & -.004 \\
\hline \multicolumn{6}{|l|}{ Cross-level } \\
\hline $\mathrm{MI} \times \mathrm{SC}$ & & & & & -.041 \\
\hline $\mathrm{MI} \times \mathrm{SD}$ & & & & & .043 \\
\hline $\mathrm{MS} \times \mathrm{SC}$ & & & & & $.266^{* *}$ \\
\hline $\mathrm{MS} \times \mathrm{SD}$ & & & & & -.119 \\
\hline $\mathrm{S} \times \mathrm{SC}$ & & & & & .002 \\
\hline $\mathrm{S} \times \mathrm{SD}$ & & & & & .061 \\
\hline $\mathrm{A} \times \mathrm{SC}$ & & & & & -.002 \\
\hline $\mathrm{A} \times \mathrm{SD}$ & & & & & .002 \\
\hline \multicolumn{6}{|l|}{ Variance component } \\
\hline Intercept & & & & $.085^{* *}$ & $.083^{* *}$ \\
\hline SC & & & & $.072 * *$ & $.061^{* *}$ \\
\hline SD & & & & $.058^{* *}$ & $.056^{* *}$ \\
\hline Deviance (parameters) & $1038.82(3)$ & $879.031(6)$ & $881.999(10)$ & 839.759 (15) & $828.308(23)$ \\
\hline
\end{tabular}

$\dagger p<.09 ;{ }^{*} p<.05 ;{ }^{* *} p<.01$

shared family identity, but identity accommodation was not a significant predictor. Moreover, the relationship between these two communicative behaviors and shared family identity varied across families. Marital status moderated the relationship between supportive communication and shared family identity. Although supportive communication was positively associated with perceptions of shared family identity in both conditions, supportive communication had a higher association with shared family identity for nonmarried families, $b=$ .471 , compared to married families, $b=.285$.

H3 was examined in the third analysis (Table 4 ). Model 1 showed that approximately $48 \%$ of the variance in shared family identity could be attributed to group-level factors (between-group variance $=.59283$; within-group variance $=.63200$ ) . The fixed effects model (Model 2) accounted for approximately $9 \%$ of the within-group variance, with supportive communication and identity accommodation emerging as significant predictors. As shown in Model 3, neither marital status nor multiracial/ethnic identity were significant predictors of group salience. Age and sex $(p s<.05)$ were significant, however, in that women were more likely to perceive higher levels of group salience in the relationships, and there was a weak but significant relationship between age and group salience. This model accounted for approximately $21 \%$ of the between-group variance. Again, supportive communication and self-disclosure had significant random effects ( $p$ s < .05), but identity accommodation did not $(p=.206)$. Results for the random coefficients model are depicted in Model 4. Relevant cross-level interactions were included in Model 5, and this final model accounted for approximately $26 \%$ of the between-group variance and approximately $31 \%$ of the within-group variance of the baseline model.

On the basis of this analysis, H3 was partially supported in that supportive communication and identity accommodation were negatively associated with ethnic group salience, but self-disclosure was not related. Again, marital status moderated 
Table 4. Analysis 3: Communicative Predictors of Group Salience

\begin{tabular}{|c|c|c|c|c|c|}
\hline & Model 1 & Model 2 & Model 3 & Model 4 & Model 5 \\
\hline \multicolumn{6}{|l|}{ Level 1} \\
\hline Intercept & $2.830 * *$ & $2.830 * *$ & $2.533^{* *}$ & $2.541^{* *}$ & $2.854^{* *}$ \\
\hline Supportive communication (SC & & $-.172^{* *}$ & $-.169^{* *}$ & $-.176^{\star *}$ & $-.287^{* *}$ \\
\hline Self-disclosure (SD) & & .060 & .059 & .042 & .041 \\
\hline Identity accommodation (IA) & & $-.243^{* *}$ & $-.246^{* *}$ & $-.225^{* *}$ & $-.230 * *$ \\
\hline \multicolumn{6}{|l|}{ Level 2} \\
\hline Multiracial/ethnic identity (M) & & & -.033 & -.029 & -.026 \\
\hline Marital status (MS) & & & -.109 & -.045 & -.037 \\
\hline $\operatorname{Sex}(S)$ & & & $.438^{* *}$ & $.389^{*}$ & $.363^{*}$ \\
\hline Age (A) & & & $.023^{* *}$ & $.022^{* *}$ & $.020^{* *}$ \\
\hline \multicolumn{6}{|l|}{ Cross-level } \\
\hline $\mathrm{MI} \times \mathrm{SC}$ & & & & & .039 \\
\hline $\mathrm{MI} \times \mathrm{SD}$ & & & & & -.057 \\
\hline $\mathrm{MS} \times \mathrm{SC}$ & & & & & $.290^{*}$ \\
\hline $\mathrm{MS} \times \mathrm{SD}$ & & & & & .020 \\
\hline $\mathrm{S} \times \mathrm{SC}$ & & & & & -.141 \\
\hline $\mathrm{S} \times \mathrm{SD}$ & & & & & .092 \\
\hline $\mathrm{A} \times \mathrm{SC}$ & & & & & .006 \\
\hline $\mathrm{A} \times \mathrm{SD}$ & & & & & .004 \\
\hline \multicolumn{6}{|l|}{ Variance component } \\
\hline Intercept & & & & $.435^{* *}$ & $.438^{* *}$ \\
\hline $\mathrm{SC}$ & & & & $.074^{*}$ & $.044 \dagger$ \\
\hline SD & & & & $.016^{*}$ & $.019 \dagger$ \\
\hline Deviance (parameters) & 1245.52(3) & $1202.43(6)$ & $1189.06(10)$ & $1161.43(15)$ & $1145.18(23)$ \\
\hline
\end{tabular}

$\dagger p<.10 ;{ }^{*} p<.05 ;{ }^{* *} p<.01$

Table 5. Analysis 4: Group Salience as a Predictor of Relational Satisfaction

\begin{tabular}{lrr}
\hline & Model 1 & Model 2 \\
\hline Level 1 & & \\
Intercept & $5.354^{* *}$ & $5.371^{* *}$ \\
Group salience & & $-.267^{* *}$ \\
Deviance (parameters) & $1531.72(3)$ & $1492.72(4)$ \\
\hline$* * p<.01$ & &
\end{tabular}

the relationship between supportive communication and group salience in that there was negative relationship between supportive communication and perceptions of group salience: married families, $b=-.382$; nonmarried families, $b=-.071$.

Because bivariate correlations do not take into account interdependence of data, $\mathrm{H} 4$ and $\mathrm{H} 5$ were also tested with MLM analysis. In support of the hypotheses (see Tables 5 and 6), group salience was a negative predictor of relational satisfaction (H4) and shared family identity (H5).
Table 6. Analysis 5: Group Salience as a Predictor of Shared Family Identity

\begin{tabular}{lrr}
\hline & Model 1 & \multicolumn{1}{c}{ Model 2 } \\
\hline Level 1 & & \\
Intercept & $4.164^{* *}$ & $4.163^{* *}$ \\
$\quad$ Group salience & & $-.121^{* *}$ \\
Deviance (parameters) & $1038.82(3)$ & $1028.03(4)$ \\
\hline
\end{tabular}

** $p<.01$

\section{Discussion}

The goal of this study was to enhance our understanding of multiracial/ethnic family functioning by investigating the relationship between family communication and the outcomes of relational satisfaction, shared family identity, and group salience. Further, we examined the potential moderating roles of multiracial/ethnic identity and marital status. The following discussion highlights how these findings complement the extant literature on 
multiracial/ethnic families and contribute to our theorizing on family functioning. Guided by an intergroup perspective that utilized the Common Ingroup Identity Model and CAT, H1 -H3 investigated the relationship between accommodative behaviors and relational outcomes. Results of the first analysis (H1) support the theoretical tenets of CAT in that supportive communication, self-disclosure, and identity accommodation were all positively associated with relational satisfaction. When we consider the well-established role of supportive communication and self-disclosure in personal relationships, the results for these two constructs are not surprising. The significant finding for identity accommodation, however, suggests that there are family communication processes that are unique and important to relational solidarity in multiracial/ethnic families and warrant further study. Moreover, this demonstrates that family scholars and practitioners should work to identify and understand behaviors important in multiracial/ethnic families that are not emphasized in the extant family scholarship such as those that communicatively recognize and affirm identity.

In contrast to $\mathrm{H} 1$, we found partial support for $\mathrm{H} 2$ in that only supportive communication and self-disclosure were significant predictors of the common in-group identity of family. The finding that identity accommodation was not a significant predictor of shared family identity is initially surprising, considering that shared family identity is a perception of common ingroup identity and this communication behavior specifically addresses identity. Whereas identity accommodation exclusively addresses the mixed heritage of the children, however, a shared family identity (or lack thereof) can be indicative of various social categorizations other than race/ethnicity (e.g., religious identity, sexual identity, political identity) or divergent values. In other words, we placed race/ethnicity as a core construct of interest in understanding issues of identity and family functioning. Yet, a more enhanced understanding of family functioning may be achieved by understanding how racial/ ethnic identity works in tandem with other social identities in affecting or reflecting family functioning. In the analyses for $\mathrm{H} 1$ and $\mathrm{H} 2$, the role of supportive communication and self-disclosure in predicting relational satisfaction and shared family identity varied across families. When we consider that the sample for this study consisted of multiple types of multiracial/ethnic families, this variation may be attributable to different cultural norms and standards in family communication. For example, in a culture that values openness, it is likely that self-disclosure would be more strongly associated with these two relational outcomes than would be expected in cultures valuing privacy. This finding suggests that multiracial/ethnic families are heterogeneous, and, hence, similarities and differences in family functioning across various types of multiracial/ethnic families should be explored in future inquiries. Relying on labels and self- or other-identified racial/ethnic grouping, however, can lead to false assumptions about the homogeneity of racial/ethnic groups (Singelis, Triandis, Bhawuk, \& Gelfand, 1995). Thus, these inquiries should focus on the cultural orientations that may influence family interactions (e.g., individualism-collectivism, centrality of family, emotional expression) and that often vary across racial/ethnic groups (Sillars, 1995).

Our third analysis (H3) examined the role of communicative behaviors in predicting racial/ethnic group salience. As expected, supportive communication and identity accommodation were associated with lower levels of perceived group differences in family relationships. Self-disclosure, however, did not emerge as a significant predictor, suggesting that perceptions of group difference cannot be ameliorated by openness unless that openness specifically addresses racial/ethnic identity concerns, as is the case with identity accommodation.

To further understand the extent to which these behaviors are associated with perceptions of family relationships, we examined the role of marital status of the participant's parents and multiracial/ethnic identity of the participant. Marital status emerged only as a significant moderator of the relationship between supportive communication and the various relational outcomes. Whereas supportive communication was associated with satisfying relationships and a stronger sense of shared family identity overall, results suggest that this association may be slightly stronger in families in which parents are not married. Considering the importance of support in postdivorce adjustment (Amato, 2000), it is likely that in not having an intact family individuals rely on or expect more supportive behaviors to engender a positive relationship or sense of inclusiveness with individual family members. In terms of group salience, as supportive communication increased, perceptions 
of racial/ethnic group differences decreased, and this association was most pronounced in married families. The rationale for this is less intuitive. It is possible, however, that being aware of distinctions in nonintact families (e.g., differences between mother's and father's family) or having limited contact with nonresidential family members may activate other distinctions such as racial/ethnic group salience regardless of the nature of the interaction. Given these findings on the moderating role of marital status, inquiries into multiracial/ ethnic family functioning should include consideration of marital status and how, if it all, this may influence dyadic and family-level interactions.

One might be surprised that the identity of a child (i.e., multiracial/ethnic identity) played no moderating or predictive role in the relationships among constructs that we have investigated in this study. Multiracial/ethnic identity is an extremely complex aspect of self-concept, however. In fact, individuals can experience multiple stages of multiracial/ethnic identity among the various dimensions of ethnicity (e.g., language, cultural artifacts, involvement in cultural events; Phinney, 1990). These dimensions were not included in our direct assessment of identity. Thus, to further our understanding, future inquiries should consider alternative and, perhaps, less direct assessments of identity to capture more thoroughly the complexity of multiracial/ethnic identity.

Finally, H5 and H6 examined the relationship between group salience, relational satisfaction, and shared family identity. As expected, group salience was negatively associated with both relational outcomes, suggesting that a common ingroup perception and satisfying relationships are contingent on minimizing perceptions of groupbased difference. Though placed within the specific context of multiracial/ethnic families, these results suggest broader theoretical implications of research on general family functioning. Specifically, an intergroup perspective on families allows us to consider various group influences that exist but are not typically examined in family scholarship (Harwood \& Giles, 2005). As such, social identity (e.g., sexual identity, religion, age) or formative (e.g., in-laws, stepfamilies) influences can create group-based impediments to a family's sense of collective identity and harmonious relationships. As we have attempted to do in the current study, identifying behaviors that both af- firm individual identity and create family solidarity is a worthy goal for family scholars. Likewise, as demonstrated by Harwood, Hewstone, Paolini, and Voci (2005), when we consider the idea that members of the same family can belong to different social out-groups (e.g., a heterosexual dad interacting with his gay son), intergroup theorizing (Brown \& Hewstone, 2005) provides a framework for investigating how family relationships may be associated with, or even improve, perceptions of social groups outside of the family (i.e., a heterosexual dad's relationship with a gay son may improve his attitudes toward homosexuality in general). In the multiracial/ ethnic context, future inquiries should explore how family functioning may influence perceptions of various racial/ethnic groups in general.

Overall, the results provide an enhanced understanding of communication in multiracial/ ethnic families and outline some theoretical implications for family scholarship. Specific limitations, however, should be taken into account when interpreting these findings that may serve as springboards for future inquiries. First, we did not examine the variations across families on the basis of racial/ethnic makeup. Given the significant between-group differences in our results, it is likely that different racial/ethnic cultural variations influence family functioning. Rather than relying solely on racial/ethnic categories to examine between-group differences, however, as is the case in much of the research on racial/ethnic influences on family functioning, future inquiries should investigate the extent to which one embraces attitudes and behaviors associated with various cultural backgrounds (e.g., collectivism, power and social hierarchy) and the extent to which these cultural orientations influence family relationships and interactions. Second, although we can make theory-based claims concerning the directional influence of certain variables, alternative research approaches such as longitudinal designs would provide a more valid assessment of the causal relationships between the constructs discussed in this study. Third, we focused on only the adult child's perspective whereas perceptions from multiple family members would provide a more holistic understanding of family interactions and a way to identify general family communication patterns related to personal and familial identity development and maintenance. Fourth, because language 
is a significant element of identity, future research should investigate the role of language proficiency and code-switching, the act of changing one's speech pattern to match that of the group within which one is speaking (e.g., McKirnan \& Hamayan, 1984), in family functioning. Finally, given that we focused on only parent and grandparent relationships, research would benefit from inclusion of other family members (e.g., siblings, multiple grandparents, children, stepparent, in-laws) to gain a better sense of other familial influences on racial/ethnic identity. Likewise, although we directed participants to answer questions about specific family relationships, we realize that there are various relationships - biological, legal, or voluntary - that are important to consider when conceptualizing "family." In light of these limitations, the findings from the current study provide insight into multiracial/ethnic family functioning and a foundation for future inquiries into this growing family form.

Acknowledgments - A previous version of this article was presented at the Central States Communication Association annual meeting, Madison, WI, in 2008. The authors thank Laci Ades for comments on earlier versions of this article. Velma McBride Murry edited the published version of this article for Journal of Marriage and Family.

\section{References}

Aiken, L. S., \& West, S. G. (1991). Multiple Regression: Testing and Interpreting Interactions. Thousand Oaks, CA: Sage.

Amato, P. R. (2000). The consequences of divorce for adults and children. Journal of Marriage and the Family, 62, 1269-1287.

Amato, P. R., \& Keith, B. (1991). Parental divorce and the well-being of children: A meta-analysis. Psychological Bulletin, 110, 26-46.

Brown, R., \& Hewstone, M. (2005). An integrative theory of intergroup contact. Advances in Experimental Social Psychology, 37, 255-343.

Brown, R. J., Vivian, J., \& Hewstone, M. (1999). Changing attitudes through intergroup contact: The effects of group membership salience. European Journal of Social Psychology, 29, 741-764.

Brunsma, D. L. (2005). Interracial families and the racial identification of mixed race children: Ev- idence from the early childhood longitudinal study. Social Forces, 84, 1131-1156.

Burleson, B. R., \& MacGeorge, E. L. (2004). Supportive communication. In M. L. Knapp \& J. A. Daly (eds.), Handbook of Interpersonal Communication (pp. 374-422). Thousand Oaks, CA: Sage.

Byrd, M. M., \& Garwick, A. W. (2006). Family identity: Black-White interracial family health experiences. Journal of Family Nursing, 12, 22-37.

Diggs, R. C., \& Clark, K. D. (2002). It's a struggle but worth it: Identifying and managing identities in an interracial friendship. Communication Quarterly, 50, 368-390.

Foeman, A., \& Nance, T. (2002). Building new cultures, reframing old images: Success strategies of interracial couples. The Howard Journal of Communication, 13, 237-249.

Gaertner, S. L., \& Dovidio, J. F. (2000). Reducing Intergroup Bias: The Common Ingroup Identity Model. Philadelphia, PA: Psychology Press.

Harwood, J., \& Giles, H. (2005). Intergroup Communication: Multiple Perspectives (pp. 1-20). New York: Peter Lang.

Harwood, J., Hewstone, M., Paolini, S., \& Voci, A. (2005). Grandparent-grandchild contact and attitudes towards older adults: Moderator and mediator effects. Personality and Social Psychology Bulletin, 31, 393-406.

Harwood, J., Raman, P., \& Hewstone, M. (2006). The family and communication dynamics of group salience. Journal of Family Communication, 6, 181-200.

Harwood, J., Soliz, J., \& Lin, M.-C. (2006). Communication accommodation theory: An intergroup approach to family relationships. In D. O. Braithwaite \& L. Baxter (eds.), Engaging Theories in Family Communication: Multiple Perspectives (pp. 19-34). Thousand Oaks, CA: Sage.

Hox, J. (2002). Multilevel Modeling: Techniques and Applications. Mahwah, NJ: Erlbaum.

Hughes, P. C., \& Dickson, F. C. (2005). Communication, marital satisfaction, and religious orientation in interfaith marriages. Journal of Family Communication, 5, 25-41.

Huston, T. L., McHale, S. M., \& Crouter, A. C. (1986). When the honeymoon's over: Changes in the marriage relationship over the first year. In $\mathrm{R}$. Gilmore \& S. W. Duck (eds.), The Emerging Field of Personal Relationships (pp. 109-132). Hillsdale, NJ: Erlbaum.

Kenny, D. A., Kashy, D. A., \& Cook, W. L. (2006). Dyadic Data Analysis. New York: Guilford Press.

Laurenceau, J. P., Barrett, L. F., \& Pietromonaco, P. R. (1998). Intimacy as an interpersonal process: The importance of self-disclosure, partner disclosure, 
and perceived partner responsiveness in interpersonal exchanges. Journal of Personality and Social Psychology, 74, 1238-1251.

McFadden, J. (2001). Intercultural marriage and family: Beyond the racial divide. The Family Journal: Counseling and Therapy for Couples and Families, 9, $39-42$.

McKirnan, D. J., \& Hamayan, E. V. (1984). Speech norms and attitudes toward outgroup member: A test of a model in a bicultural context. Journal of Language and Social Psychology, 3, 21-38.

Orbe, M. P. (1999). Communication about "race" in interracial families. In T. J. Socha \& R. C. Diggs (eds.), Communication, Race, and Family: Exploring Communication in Black, White, and Biracial Families (pp. 167-180). Mahwah. NJ: Erlbaum.

Pierce, G. R., Sarason, I. G., \& Sarason, B. R. (1991). General and relationship-based perceptions of social support: Are two constructs better than one? Journal of Personality and Social Psychology, 61, 1028-1039.

Phinney, J. S. (1990). Ethnic identity in adolescents and adults: Review of research. Psychological Bulletin, 108, 499-514.

Phinney, J. S. (2000). Identity formation across cultures: The interaction of personal, societal, and historical change. Human Development, 43, 27-31.

Rockquemore, K. A., \& Brunsma, D. A. (2002). Socially embedded identities: Theories, typologies, and processes of racial identity among biracials. Sociological Quarterly, 43, 335-356.

Root, M. P. P. (1996). Racially Mixed People in the New Millennium. Newbury Park, CA: Sage.

Root, M. P. P. (2003). Multiracial families and children: Implications for educational research and practice. In J. A. Banks \& C. A. McGee Banks (eds.), Handbook of Research on Multicultural Education (pp. 110-124). San Francisco: Jossey- Bass.

Shepard, C., Giles, H., \& LePoire, B. A. (2001). Communication accommodation theory. In W. P.
Robinson \& H. Giles (eds.), The New Handbook of Language and Social Psychology (pp. 33-56). Chichester, UK: Wiley.

Sillars, A. L. (1995). Communication and family culture. In M. A. Fitzpatrick \& A. L. Vangelisti (eds.), Explaining Family Interactions (pp. 375-399). Thousand Oaks, CA: Sage.

Singelis, T. M., Triandis, H. C., Bhawuk, D., \& Gelfand, M. (1995). Horizontal and vertical dimensions of individualism and collectivism: A theoretical and measurement refinement. Journal of Comparative Social Science, 29, 240-275.

Soliz, J., \& Harwood, J. (2006). Shared family identity, age salience, and intergroup contact: Investigation of the grandparent-grandchild relationship. Communication Monographs, 73, 87-107.

Troy, A. B., Lewis-Smith, J., \& Laurenceau, J.-P. (2006). Interracial and intraracial romantic relationships: The search for differences in satisfaction, conflict, and attachment style. Journal of Social and Personal Relationships, 23, 65-80.

Vivero, J. J., \& Jenkins, S. R. (1999). Existential hazards of the multicultural individual: Defining and understanding cultural homelessness. Cultural Diversity and Ethnic Minority Psychology, 5, 6-26.

Vonofakou, C., Hewstone, M., \& Voci, A. (2007). Contact with out-group friends as a predictor of metaattitudinal strength and accessibility of attitudes towards gay men. Journal of Personality and Social Psychology, 92, 804-820.

Wallace, K. R. (2004). Situating multiethnic identity: Contributions of discourse theory to the study of mixed heritage students. Journal of Language, Identity, and Education, 3, 195-213.

Williams, T. K. (1996). Race as process: Reassessing the "What are you?" encounters of biracial individuals. In M. P. Root (ed.), The Multiracial Experience: Racial Borders as the New Frontier (pp. 191209). Thousand Oaks, CA: Sage. 